\title{
Alternativa sustentável para destinação de resíduos de construção classe A: sistemática para reciclagem em canteiros de obras
}

\author{
Sustainable alternative for the disposal of Class $A$ \\ construction residues: a process for recycling in building \\ sites
}

\section{Patricia Pereira de Abreu Evangelista \\ Dayana Bastos Costa \\ Viviana Maria Zanta}

\section{Patricia Pereira de Abreu \\ Evangelista \\ Serviço Nacional de Aprendizagem Industrial Av. Dendezeiros, 99, Bonfim Salvador - BA - Brasil CEP: $41770-395$ Tel.: (71) 3310-9983} E-mail: patriciae@fieb.org.br

\footnotetext{
Dayana Bastos Costa Departamento de Construção e Estruturas Universidade Federal da Bahia Av. Aristides Novis, 02, Federação

Salvador - BA - Brasil CEP: $40210-630$ Tel.: (71) 3283-9731
} E-mail: dayanabcosta@ufba.br

Viviana Maria Zanta Departamento de Engenharia Ambiental Universidade Federal da Bahia Av. Aristides Novis, 02, $4^{\circ}$ andar, Federação

Salvador - BA - Brasil CEP: $40210-630$ Tel.: (71) 3283-9454 E-mail: zanta@ufba.br

Recebido em 15/04/2010 Aceito em 20/07/2010
Resumo

indústria da construção civil apresenta-se como um dos segmentos industriais mais críticos no que se refere aos impactos ambientais, sendo o principal gerador de resíduos sólidos da sociedade. Neste sentido, a cidade de Salvador, Bahia, é caracterizada pela geração de grande volume de resíduos de construção civil, pelo esgotamento das áreas para recepção dos resíduos gerados pela atividade construtiva e pela inexistência de áreas de transbordo, de triagem e de usinas para reciclagem. O presente trabalho apresenta uma proposta de sistematização para o processo de reciclagem de resíduos de construção classe A em canteiros de obra, considerando aspectos técnicos, econômicos e ambientais. O processo de reciclagem foi estruturado e validado por meio da realização de três estudos de caso de experiência de reciclagem em canteiros de obra de Salvador, utilizando equipamento móvel de britagem. Foram desenvolvidos um fluxograma e um procedimento operacional para apoiar a realização da reciclagem nos canteiros, assim como foram gerados parâmetros para avaliação do referido processo. Este trabalho mostra o potencial da reciclagem em canteiros de obras como uma alternativa para a destinação dos resíduos de construção civil, indicando ações que facilitem a adoção dessa prática, de forma a contribuir para a redução dos impactos ambientais causados pelo descarte inadequado dos resíduos de construção.

Palavras-chave: Resíduo de construção civil. Reciclagem em canteiro de obras. Sustentabilidade.

\section{Abstract \\ The construction industry is one of the most critical industrial segments in terms of environmental impacts, and it is the main producer of solid waste in our society. In this respect, in the city Salvador, Bahia, although a huge amount of construction waste is produced, the areas for the disposal of such waste are very limited, there are no facilities for exchanging and selecting construction waste, and there is a shortage of recycling facilities. This study proposes a method to implement a construction waste recycling process in construction sites, considering technical, economical and environmental aspects. A set of case studies was conducted in three construction sites in Salvador, using portable equipment for construction waste recycling. The main result was the development of a flowchart and an operational procedure aimed at supporting the implementation of a construction waste recycling process on site. This research study indicates the potential of construction waste recycling on site as an alternative for the disposal of waste elsewhere, prescribing a set of actions designed to facilitate the incorporation of recycling practices, with the aim of contributing for the reduction of the environmental impacts caused by the inappropriate destination of construction waste. \\ Keyword: Construction waste. Recycling in construction sites. Sustainability.}




\section{Introdução}

Em 1992, a Conferência das Nações Unidas sobre Meio Ambiente e Desenvolvimento, realizada no Rio de Janeiro, a Rio-92, demonstrou um aumento do interesse mundial pelo futuro do planeta. Muitos países passaram a valorizar as relações entre desenvolvimento socioeconômico e modificações no meio ambiente (LORDÊLO; EVANGELISTA; FERRAZ, 2007).

A Agenda 21 foi um dos principais resultados da Rio-92. Esse documento, resultado de um acordo firmado entre 179 países, reforça a necessidade e a importância de cada país se comprometer a refletir, global e localmente, sobre a forma pela qual governos, empresas, organizações e todos os demais setores da sociedade poderiam cooperar no estudo de soluções para os problemas socioambientais (LORDÊLO; EVANGELISTA; FERRAZ, 2007).

De acordo com as mesmas autoras, naquela época, não se percebia uma preocupação por parte da indústria da construção civil com os impactos ambientais causados por sua cadeia produtiva, a exemplo do esgotamento dos recursos naturais não renováveis que eram utilizados ao longo de todo o seu processo de produção, nem tampouco com o destino dado aos resíduos gerados. Entretanto, o setor da construção civil apresenta-se como um dos setores mais críticos no que diz respeito aos impactos ambientais, pois é responsável por cerca de $50 \%$ do $\mathrm{CO}_{2}$ lançado na atmosfera e por quase metade da quantidade dos resíduos sólidos gerados no mundo (JOHN, 2000).

Em Salvador, onde é significativa a geração de resíduos sólidos urbanos, o crescimento populacional, o desenvolvimento econômico e a utilização de tecnologias inadequadas têm contribuído para que essa quantidade aumente ainda mais. Em um momento caracterizado pelo forte aquecimento do setor imobiliário na cidade, torna-se urgente a necessidade de soluções alternativas para a destinação dos resíduos de construção civil (RCC).

Na capital baiana, os RCC geridos pelo poder público representam quase a metade do resíduo sólido urbano (RSU) e correspondem à geração diária de aproximadamente 2.300 t (SALVADOR, 2006). O volume de geração dos RCC no município é muito maior que o dado apresentado, considerando que este não inclui os resíduos manejados pela iniciativa privada.

Em um momento no qual ficam cada vez mais restritas as áreas disponíveis para a disposição de RCC, é fundamental para o desenvolvimento sustentável da cadeia produtiva da construção civil que todos os envolvidos busquem, conjuntamente, o encaminhamento de soluções ambientalmente responsáveis, por meio da redução, reaproveitamento e reciclagem desses resíduos, visando à minimização dos impactos causados.

A reciclagem, em diversos estudos (CARNEIRO et al., 2001; JOHN, 2000; LEITE, 2001), é citada como uma alternativa para a redução da quantidade de resíduos dispostos nos aterros, além de ser uma proposta sustentável para a destinação dos RCC. Apesar dessa unanimidade, poucas são as iniciativas públicas e privadas na adoção dessa prática. São pontuais as legislações municipais específicas sobre o tema, as ações de estímulo à utilização dos agregados reciclados em obras públicas e privadas, a implantação de usinas de reciclagem e a prática desta nos canteiros de obra, refletindo-se na falta de informações consistentes sobre o volume de agregado reciclado gerado no país.

Apesar das iniciativas públicas locais, como o Projeto de Gestão Diferenciada do Entulho da Empresa de Limpeza Urbana de Salvador (LIMPURB) (SALVADOR, 2006), e a Resolução $n^{\circ} 307$ do Conselho Nacional do Meio Ambiente (CONAMA) (BRASIL, 2002), específica para o setor da construção civil, ainda é muito pequena a quantidade de empresas de construção civil da capital baiana que realizam a gestão eficiente dos resíduos em seus canteiros.

Menor ainda é a prática do reaproveitamento e da reciclagem. A segregação, o acondicionamento e a disposição final qualificada dos resíduos ainda não são realizados de forma adequada e integrada às atividades produtivas dos canteiros da maior parte do Brasil (LORDÊLO; EVANGELISTA; FERRAZ, 2007).

Muitos são os estudos relacionados à caracterização do entulho de obras e dos agregados reciclados, assim como suas possíveis aplicações em materiais de construção com desempenho similar ao dos agregados naturais (LEITE, 2001; TENÓRIO et al., 2008; VIEIRA; DAL MOLIN, 2004). Existe também norma técnica (NBR 15116) que trata da viabilidade do uso do agregado reciclado na produção de concretos sem função estrutural, argamassas, blocos, pavimentos, entre outras aplicações (ABNT, 2004h). Porém, são poucos os estudos acerca do processo de reciclagem nos canteiros com uma análise mais ampla de sua gestão.

Considerando os aspectos citados, faz-se necessário ampliar as pesquisas no campo da avaliação do processo de reciclagem nos canteiros 
de obras e no estabelecimento de diretrizes para ampliação dessa prática como uma alternativa para minimizar os impactos socioambientais causados pelo descarte inadequado desses resíduos, preservar recursos naturais e melhorar a qualidade de vida nas áreas urbanas.

Nesse sentido, este trabalho tem como objetivo propor a sistematização de procedimentos para o processo de reciclagem de resíduos de construção classe A em canteiros de obras, a partir de considerações técnicas, econômicas e ambientais.

Este trabalho foi desenvolvido dando continuidade ao Projeto de Gerenciamento Integrado de Resíduos da Construção Civil: Redução, Reciclagem e Reutilização como Alternativa Sustentável para Gestão dos Resíduos Classe A BRASIL, 2002), financiado pelo Departamento Nacional do Serviço Nacional de Aprendizagem Industrial (SENAI-DN), com a participação dos estados de Sergipe, Bahia, Pernambuco e Ceará. A partir desse projeto adquiriu-se equipamento móvel de britagem visando desenvolver pesquisa acerca da reciclagem dos RCC em canteiros de obras e a aplicação dos agregados reciclados em materiais de construção. Esse equipamento foi utilizado ao longo deste trabalho.

\section{Gestão de resíduos de construção}

\section{Resíduos de construção civil}

Segundo a NBR 10004 (ABNT, 2004a), resíduos sólidos são "resíduos nos estados sólidos e semisólidos, que resultam de atividades de origem industrial, doméstica, hospitalar, comercial, agrícola, de serviços e de varrição". Na classificação dos resíduos quanto aos riscos potenciais ao meio ambiente e à saúde pública, estabelecida por essa mesma norma, os resíduos de construção civil (RCC) são enquadrados na classe II B - Inertes. Isso quer dizer que esses resíduos, quando submetidos ao ensaio de solubilização, realizado segundo a NBR 10006 (ABNT, 2004b), não devem ter qualquer um de seus componentes solubilizados em concentrações superiores aos padrões de potabilidade da água.

De acordo com a Resolução n $^{\circ} 307$ do CONAMA (BRASIL, 2002), os RCC são provenientes de construções, reformas, reparos e demolições de obras de construção civil, e os resultantes da preparação e da escavação de terrenos, tais como tijolos, blocos cerâmicos, concreto em geral, solos, rochas, metais, resinas, colas, tintas, madeiras e compensados, forros, argamassas, gesso, telhas, pavimento asfáltico, vidros, plásticos, tubulações, fiação elétrica, etc., comumente chamados de entulhos de obras, caliça ou metralha.

Os RCC são estratificados em quatro classes (A, $\mathrm{B}, \mathrm{C}$ e D). Os resíduos classe A, foco do presente trabalho, são os resíduos reutilizáveis ou recicláveis como agregado, decorrentes de construção, demolição, reformas e reparos de pavimentação e de edificações, e da fabricação ou demolição de pré-moldados produzidos em canteiros.

A Resolução n 307 do CONAMA (BRASIL, 2002) foi elaborada com o objetivo de estabelecer diretrizes, critérios e procedimentos para a gestão dos RCC, disciplinando as ações necessárias para minimizar os impactos ambientais. A referida resolução, que entrou em vigor em 2 de janeiro de 2003, considera que os geradores de resíduos da construção civil devem ser responsáveis pelos RCC, obrigando ainda os gestores municipais e construtores a adaptar seus processos de gestão, de modo a garantir a destinação ambientalmente correta desses resíduos. Isso envolve a qualificação e a documentação de procedimentos de triagem, acondicionamento e disposição final dos resíduos no canteiro.

Segundo essa resolução, os geradores devem ter como objetivo maior a não geração de resíduos e, secundariamente, a redução, a reutilização, a reciclagem e a destinação final. Além disso, a Resolução exige dos grandes geradores a elaboração e a implantação do Projeto de Gerenciamento de Resíduos da Construção Civil (PGRCC).

Já para os municípios, a Resolução n ${ }^{\circ} 307$ do CONAMA (BRASIL, 2002) determina que eles devem implantar a gestão dos resíduos da construção civil por meio da elaboração do Plano Integrado de Gerenciamento de Resíduos da Construção Civil.

Apesar dos prazos estabelecidos para as adequações por parte dos municípios e dos geradores, foram implementadas poucas iniciativas públicas e privadas para atender às exigências estabelecidas, no sentido de adaptarem seus processos, de modo a garantir a destinação ambientalmente correta dos RCC.

Por outro lado, observa-se um esforço na elaboração de normas técnicas para a regulamentação do manejo dos resíduos sólidos de construção, assim como para a utilização dos agregados reciclados. Essas normas têm papel fundamental no sentido de estimular a segregação, reciclagem e destinação responsável dos resíduos, dando respaldo técnico e legal. Atualmente, existem cinco normas brasileiras relacionadas ao tema Gestão de Resíduos de Construção: 
(a) NBR 15112 - Resíduos da Construção Civil e Resíduos Volumosos - Áreas de Transbordo e Triagem - Diretrizes para Projeto, Implantação e Operação (ABNT, 2004d);

(b) NBR 15113 - Resíduos Sólidos da Construção Civil e Resíduos Inertes - Aterros - Diretrizes para Projeto, Implantação e Operação (ABNT, 2004e);

(c) NBR 15114 - Resíduos Sólidos da Construção Civil - Áreas de Reciclagem - Diretrizes para Projeto, Implantação e Operação (ABNT, 2004f);

(d) NBR 15115 - Agregados Reciclados de Resíduos Sólidos da Construção Civil - Execução de Camadas de Pavimentação - Procedimentos (ABNT, 2004g); e

(e) NBR 15116 - Agregados Reciclados de Resíduos Sólidos da Construção Civil - Utilização em Pavimentação e Preparo de Concreto sem Função Estrutural - Requisitos (ABNT, 2004h).

\section{Caracterização, geração e destinação dos RCC}

Para se avaliar a composição média dos RCC, vários fatores devem ser considerados, tais como a tipologia construtiva utilizada, as técnicas construtivas existentes e os materiais disponíveis em cada região. Ainda nesse contexto, devem ser considerados os índices de perdas de materiais mais significativos, ou seja, a composição do RCC também é um reflexo dos insumos que têm os índices de desperdício mais elevados no setor. Todos esses fatores influenciarão a composição do resíduo de construção e demolição (LEITE, 2001).

Segundo Vieira e Dal Molin (2004), quando se analisa a composição dos resíduos de construção e demolição das cidades, percebe-se que sua composição, em geral, possui elevados percentuais de concreto, material cerâmico e argamassa, independentemente da região, estado e até mesmo país em que foram gerados.

Pesquisa realizada em obras na Holanda reforça a afirmação dos autores anteriormente citados, indicando que $80 \%$ dos RCC são gerados a partir do uso de rochas, concretos, elementos sílicoalcalinos e materiais de cobertura (BOSSINK; BROUWERS, 1996).

Com relação à geração de RCC, esta varia com o tipo de cidade e sua população, assim como com o patamar de desenvolvimento econômico. No Brasil, em cidades de médio e grande portes, as taxas de geração desses resíduos variam entre 400 e $700 \mathrm{~kg} / \mathrm{habitante} / \mathrm{ano}$ (OLIVEIRA; OLIVEIRA; FERREIRA, 2008). Entretanto, o déficit habitacional no país pressiona a sociedade a expandir o número de habitações nos próximos anos, o que contribui ainda mais para o aumento da geração de entulho.

Comparando a geração de resíduos no Brasil e na Comunidade Europeia, observa-se que as taxas encontram-se na mesma ordem de grandeza. Segundo Puig (2006), a partir de informe da Comissão Europeia de 1999, as estimativas de geração de RCC na União Europeia variavam desde os $720 \mathrm{~kg} /$ habitante/ano, na Alemanha e Holanda, aos $170 \mathrm{~kg} / \mathrm{habitante} / \mathrm{ano}$ na Irlanda e na Grécia, estando a média dos países membros em $480 \mathrm{~kg} /$ habitante/ano.

Com relação à destinação dos RCC, esta é de responsabilidade de seu gerador, incluindo ações voltadas a seu reúso, reciclagem ou destinação responsável (BRASIL, 2002). No Brasil, são gastos em torno de $\mathrm{R} \$ 2$ milhões por mês com o recolhimento de entulho disposto clandestinamente em centros urbanos acima de 2 milhões de habitantes. Pode-se dizer que mais da metade do entulho é disposto irregularmente na maioria dos centros urbanos brasileiros de médio e grande portes (BLUMENSCHEIN, 2007).

Por outro lado, ainda são restritas, em muitos municípios, as alternativas para a destinação ambientalmente adequada dos RCC. Entre as alternativas de destinação para o resíduo classe A, pode ser indicada a reciclagem em obra para produção de areia e brita. Deve-se atentar para o fato de que alternativas para destinação podem surgir com o desenvolvimento tecnológico, alterações no mercado, políticas públicas, iniciativas privadas, entre outras possibilidades. Segundo Souza et al. (2004), embora seja de grande importância a destinação adequada dos resíduos gerados, tornam-se imperativas ações que tenham como objetivo a redução do entulho diretamente na fonte de geração, ou seja, nos próprios canteiros de obras.

\section{Reciclagem de resíduos classe $\mathrm{A}$}

A reciclagem de resíduos da construção não é uma prática nova, e sua maior difusão deu-se após a Segunda Guerra Mundial, inicialmente na Alemanha e posteriormente nos demais países da Comunidade Europeia. Em praticamente todos os países-membro existem instalações de reciclagem de RCC, normas e políticas para esse tipo de resíduo, além de uma proposta para consolidação de normativa única de toda a Comunidade. No Japão e nos Estados Unidos a reciclagem também tem sido bastante difundida e utilizada (PINTO, 1999).

No Brasil a reciclagem dos RCC é mais recente. Segundo Pinto (1999), alguns estudos foram 
realizados no início da década de 80 , utilizando "masseiras-moinho", equipamento de pequeno porte que possibilita a moagem intensa de resíduos menos resistentes para reutilização. Entretanto, essa prática está ainda muito atrasada e ocorre em escala reduzida se comparada a outros países, apesar de a construção civil do país apresentar enorme potencial de ampliação.

Como consequência do atraso da reciclagem, a utilização de agregados reciclados em larga escala também não é prática difundida entre os municípios brasileiros. A implantação de usinas de reciclagem com produção regular e padrões de qualidade definidos ainda não se transformou em rotina adotada pelas prefeituras, nem pela iniciativa privada. Apesar disso, alguns municípios estão procurando se organizar para adotar uma política de gerenciamento de seus resíduos sólidos com o objetivo de transformá-los, de forma empresarial, em agregados reciclados (LEVY, 2001).

A concentração das iniciativas públicas para a reciclagem de RCC está localizada nos estados de São Paulo e Minas Gerais. Em Belo Horizonte foi estabelecido um amplo plano de gestão para os resíduos da construção civil que conta com três usinas de reciclagem de entulho (MINAS GERAIS, 2006). Vários municípios paulistas também apresentam soluções para a destinação adequada dos RCC, a exemplo de Campinas, Guarulhos, Americana, Ribeirão Preto e São Carlos (EVANGELISTA, 2009).

A reciclagem, além de ser promovida em instalações permanentes, pode ser realizada no próprio canteiro, utilizando equipamentos móveis. Essa abordagem remete à execução dos processos de britagem e peneiramento no próprio local de produção dos resíduos e de utilização do agregado reciclado logo que é processado. Tal prática reduz o consumo de agregados naturais, a destinação em aterros, os custos de transporte, energia e desgaste com estradas e equipamentos (GOONAN, 2000). Apesar de pouco disseminadas, algumas iniciativas de reciclagem em canteiros de obras podem ser identificadas em municípios como São Paulo, Maceió, Brasília, Aracaju e Salvador (EVANGELISTA, 2009).

Devidamente reciclado, o entulho apresenta propriedades físicas e químicas apropriadas para seu emprego como material de construção. No entanto, os RCC são formados de uma grande variedade de componentes. A proporção desses materiais em diferentes amostras é muito variável e de grande heterogeneidade. Esse é um dos motivos da baixa utilização de agregados reciclados, o que dificulta seu aproveitamento pela indústria (VIEIRA; DAL MOLIN, 2004).

Vários estudos já foram realizados para avaliar a viabilidade técnica, e em alguns casos econômica, da utilização de agregados reciclados de RCC na fabricação de materiais de construção como concretos, argamassas, blocos de concreto, elementos pré-moldados e em pavimentação. A seguir são citados alguns desses estudos.

Vieira e Dal Molin (2004) realizaram pesquisa para avaliar a viabilidade técnica e econômica da utilização de agregados reciclados provenientes de resíduos de construção e demolição em concretos. As autoras realizaram uma comparação entre concretos produzidos com agregados naturais e reciclados com substituições da ordem de $50 \%$ e $100 \%$ de agregados graúdos (AGR) e miúdos (AMR) em cinco composições. Os resultados da pesquisa indicaram que os agregados reciclados em proporções devidamente dosadas podem melhorar algumas propriedades do concreto, como sua resistência a compressão e durabilidade.

Sales e Santos (2009) desenvolveram um trabalho que objetivou estudar as características físicas e mecânicas de blocos para alvenaria, sem função estrutural, produzidos com agregado reciclado. O agregado em questão foi britado no próprio canteiro da obra, e os blocos foram produzidos na fábrica de pré-moldados da mesma empresa. Foram produzidos blocos com dois traços em massa (1:12 e 1:13) e com consumo de cimento similar ao aplicado na fabricação dos blocos convencionais. Para os dois traços produzidos com agregado reciclado, os resultados obtidos quanto à resistência a compressão foram superiores em quase $50 \%$ se comparados aos resultados dos blocos produzidos com agregado natural (SALES; SANTOS, 2009).

Motta (2005) desenvolveu pesquisa com o objetivo de avaliar aspectos físicos e o comportamento mecânico de agregados reciclados de RCC para uso em camadas de base, sub-base ou reforço do subleito, com enfoque em vias de baixo volume de tráfego. Os resultados de resistência apresentaramse satisfatórios e outros precisam ser mais aprofundados. Concluiu-se que o agregado reciclado de RCC tem uso promissor como insumo na construção de bases, sub-bases e reforços do subleito de vias de baixo volume de tráfego, em substituição aos materiais convencionais.

Para Goonan (2000), o futuro dos agregados reciclados será impulsionado pela indisponibilidade de aterros, por uma maior aceitação do produto, pelas políticas governamentais de incentivo ao uso dos agregados reciclados, bem como pelas exigências ambientais e de uma economia sã. 


\section{Método de pesquisa}

Em função do objetivo deste trabalho, da escassez de experiências semelhantes e da existência de vários elementos de análise envolvidos no processo de reciclagem em canteiros de obras, optou-se pelo estudo de caso como estratégia de pesquisa.

A pesquisa foi estruturada em etapas. A primeira envolveu uma revisão bibliográfica sobre o tema. $\mathrm{Na}$ segunda etapa realizaram-se dois estudos de caso visando entender o processo de reciclagem no canteiro, bem como desenvolver uma primeira proposta da sistemática, incluindo a identificação do melhor fluxo de atividades, a observação da interação desse processo com o andamento da obra, o levantamento de parâmetros para o dimensionamento da equipe, a identificação de possíveis aplicações para o agregado reciclado no canteiro e a análise de fatores intervenientes facilitadores ou dificultadores do processo. $\mathrm{Na}$ terceira etapa foi realizado um estudo de caso para validação da sistemática proposta na segunda etapa. Na última etapa, para favorecer a prática da reciclagem dos resíduos de construção classe A nos canteiros de obras, desenvolveu-se um fluxograma e um procedimento operacional, visando orientar as empresas interessadas em implantar o referido processo em seus canteiros.

Com o apoio do SENAI-BA e do Sindicato da Indústria da Construção Civil do Estado da Bahia (SINDUSCON-BA), três obras foram selecionadas para a realização dos estudos de caso, conforme o Quadro 1.

Em todos os estudos de caso utilizous-e equipamento móvel de britagem (britador de mandíbulas modelo URM 2015 do fabricante Fragmine). Esse equipamento é dotado de britador de mandíbulas e sistema de peneiramento, com possibilidade do uso simultâneo de duas peneiras, além de dois vibradores elétricos para deslocar o agregado britado. Pela existência de duas peneiras é possível obter duas frações granulométricas, aproveitando inclusive para rebritagem ou reúso a parcela do resíduo que não passa na peneira superior. O equipamento possui cinco peneiras (4,8 mm, 9,5 mm, 12,5 mm, $19 \mathrm{~mm}$ e $25 \mathrm{~mm}$ ), que permitem a geração de agregados miúdos e graúdos em diversas granulometrias. O equipamento móvel tem peso total aproximado de três toneladas e capacidade produtiva máxima que varia entre 1,5 e $4 \mathrm{~m}^{3}$ de resíduo britado por hora, em função da abertura do britador de mandíbulas. Quanto maior a abertura, maior a produtividade. Na produção de agregados para a construção civil a produtividade máxima desse equipamento é estimada em $2,5 \mathrm{~m}^{3}$ por hora.

Os estudos de caso foram realizados com base no fluxo e nas atividades detalhados na Figura 1.

Conforme a Figura 1, as atividades iniciais do estudo de caso envolveram a mobilização das empresas e obras, a caracterização inicial dessas obras, assim como a estruturação do processo de reciclagem, incluindo layout do canteiro para a definição do local de instalação da recicladora, de segregação do resíduo classe A e de armazenamento para o agregado reciclado.

A caracterização do resíduo classe A segregado foi realizada segundo a NBR 10007 (ABNT, 2004c). Com base nessa caracterização, foram definidas, em conjunto com os responsáveis pelas obras, as aplicações para os agregados reciclados e as respectivas granulometrias necessárias. A definição da aplicação dos agregados reciclados foi estruturada conforme a NBR 15116 (ABNT, 2004h), o que determinou o ajuste do equipamento móvel.

A atividade de monitoramento envolveu a coleta dos dados volume de resíduo britado, tempo de produção e volume de agregado reciclado nas diferentes granulometrias, além de ocorrências. Com esses dados foi possível medir o volume total de resíduos $\left(\mathrm{m}^{3}\right)$, produtividade global e produtividade do equipamento ( $\mathrm{m}^{3} /$ hora), a produção de agregado reciclado $\left(\mathrm{m}^{3}\right)$ e a relação entre volume de agregado reciclado e resíduo de construção.

\begin{tabular}{|l|l|l|l|l|}
\hline Obra & Porte & \multicolumn{1}{|c|}{ Tipo de obra } & \multicolumn{1}{c|}{$\begin{array}{c}\text { Área } \\
\text { construída }\end{array}$} & \multicolumn{1}{|c|}{ Fase da obra } \\
\hline 1 & Médio & Multipavimentos residenciais & $10.000 \mathrm{~m} 2$ & $\begin{array}{l}\text { Alvenaria e } \\
\text { revestimento }\end{array}$ \\
\hline 2 & Grande & Unidades habitacionais & $43.359 \mathrm{~m} 2$ & $\begin{array}{l}\text { Estrutura e } \\
\text { revestimento }\end{array}$ \\
\hline 3 & Grande & $\begin{array}{l}\text { Condomínio residencial vertical de } \\
\text { alto padrão com } 18 \text { torres }\end{array}$ & $320.000 \mathrm{~m} 2$ & Estrutura e alvenaria \\
\hline
\end{tabular}

Quadro 1 - Perfil das empresas dos estudos de caso 


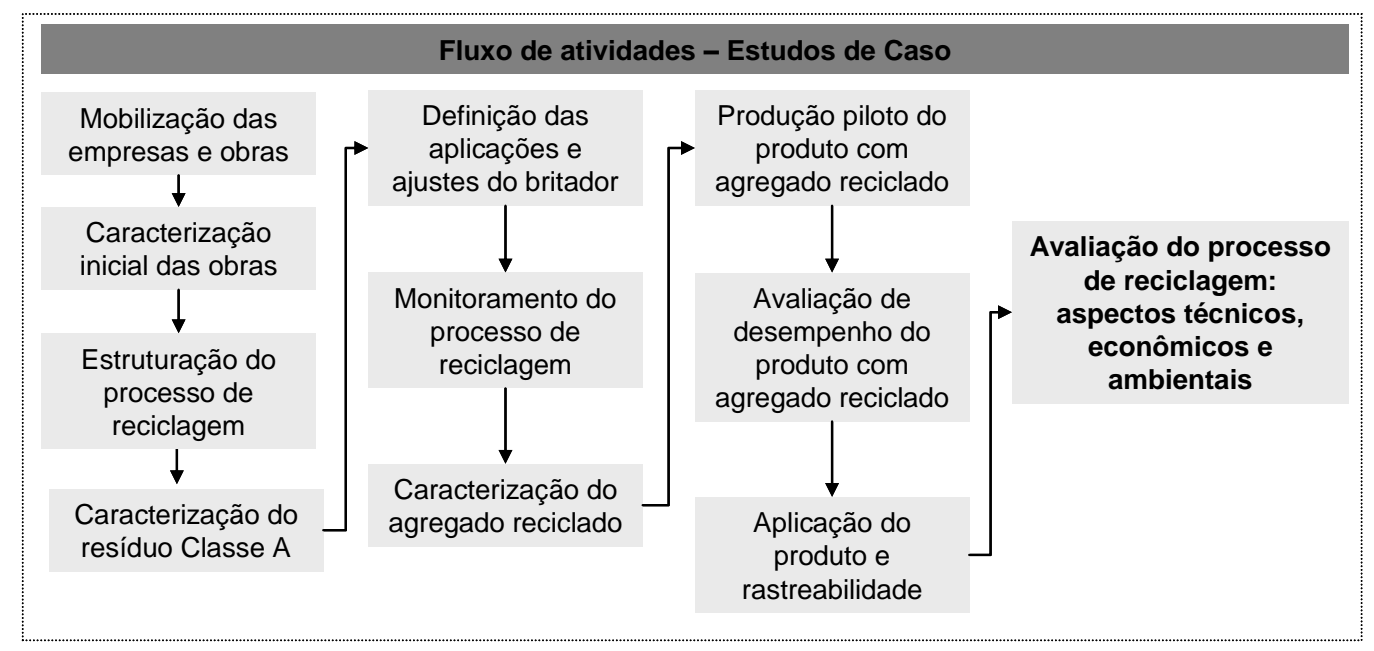

Figura 1 - Fluxo de atividades dos estudos de caso

A caracterização dos agregados reciclados foi realizada com base nos parâmetros definidos na NBR 15116 (ABNT, 2004h). É importante ressaltar que esses ensaios foram realizados por laboratórios de tecnologia contratados pela obra em estudo, sem a interferência dos pesquisadores. Em função dos resultados da caracterização dos agregados reciclados, definiram-se as matrizes experimentais dos materiais a serem produzidos, considerando diferentes percentuais de substituição de agregados reciclados, realizando, dessa forma, a produção piloto.

A avaliação técnica dos materiais produzidos foi realizada comparando-se o desempenho dos materiais produzidos com agregados reciclados com aqueles produzidos com os agregados naturais, tomando-se como referência os padrões normativos e pesquisas existentes para cada tipo de material. O produto considerado mais adequado foi aquele que utilizou o maior percentual de agregado reciclado, mantidos os padrões de desempenho requeridos. Os produtos aprovados foram aplicados nas obras, com a identificação dos locais de aplicação.

Quanto à avaliação econômica, realizous-e levantamento dos custos do agregado natural, do bota-fora de entulho e dos custos associados à produção do agregado reciclado (mão de obra direta, equipamentos, manutenção e energia). Com esses dados calculou-se o indicador de ganho econômico do processo por metro cúbico. Foi levantado ainda o investimento realizado para estruturar o processo de reciclagem no canteiro, assim como o tempo de retorno para recuperação do referido investimento e o ganho econômico a partir desse momento.

$\mathrm{Na}$ avaliação ambiental foram considerados os aspectos qualitativos relacionados, que contemplam desde a preservação dos recursos naturais não renováveis até a redução do impacto ambiental causado pelo descarte inadequado dos RCC. Essa análise foi feita tendo como referência a quantidade total de resíduos processados e o volume de agregados reciclados utilizado.

\section{Apresentação dos resultados}

Este item apresenta o Estudo de Caso 3, visando exemplificar a proposta de sistematização do processo de reciclagem em canteiros de obras.

\section{Definições iniciais do processo de reciclagem na obra}

O Estudo de Caso 3 foi realizado na obra 3, conforme características apresentadas no Quadro 1. Esse estudo foi realizado no período de julho a outubro de 2009.

A possibilidade da reciclagem dos resíduos classe A no próprio canteiro mostrou-se como uma excelente alternativa para a destinação responsável dos resíduos nessa obra. A decisão foi tomada pelos gestores do empreendimento, considerando o porte da obra, o processo construtivo e os materiais utilizados, as dificuldades identificadas para a destinação dos RCC em Salvador e a própria filosofia sustentável da empresa.

No diagnóstico inicial identificou-se que a empresa não possuía nenhuma sistemática para gestão dos RCC no canteiro. Dessa forma, foi necessário o estabelecimento de uma estratégia para a segregação dos resíduos classe A nos locais onde ele fosse gerado (por torre) e a estruturação de uma central de reciclagem para onde o resíduo segregado deveria ser enviado. A estratégia inicial foi a instalação da central de reciclagem próximo à 
central de concreto, para aproveitamento do resíduo dessa fonte.

Foi definida pela direção da obra a equipe responsável pela reciclagem no canteiro, sendo esta constituída pelo engenheiro responsável pela obra da área externa (clube e vias), por um estagiário de engenharia e por três operários para operação do britador, alimentação da máquina e coleta e armazenamento do agregado reciclado.

\section{Estruturação do processo de reciclagem}

$\mathrm{Na}$ estruturação do processo de reciclagem, foram preparadas as áreas para instalação do equipamento de britagem, segregação dos resíduos classe A e armazenamento do agregado reciclado, conforme a Figura 2.

A máquina foi posicionada em base regularizada em nível abaixo do local de segregação do resíduo classe A, para facilitar sua alimentação. Na mesma altura do caixão de alimentação foi montada a central de operação da máquina, permitindo ao operário responsável o acompanhamento do processo e identificação de possíveis problemas durante a britagem. Foi construída, próximo ao caixão de alimentação do britador, uma caixa com a dimensão de $2 \mathrm{~m}^{3}$, que foi usada como referência de volume para medir a produtividade do equipamento.

No primeiro momento, priorizou-se o resíduo gerado pela central de concreto, que, em função da grande dimensão das placas, passava por uma etapa de redução de suas dimensões por meio de rompimento por martelete com um operário extra

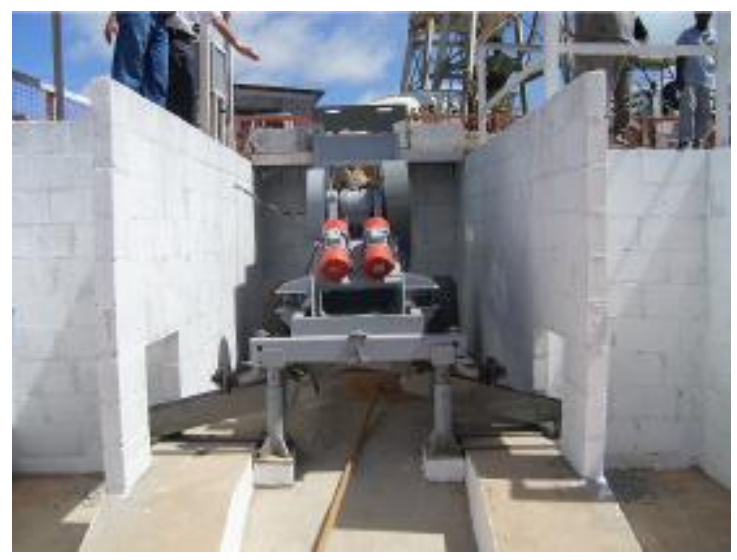

(a)

Figura 2 - Central de reciclagem do Estudo de Caso 3
(Figura 3). Em paralelo foram construídas baias para armazenamento dos agregados reciclados nas três granulometrias geradas, como pode ser visto na Figura 4.

A atividade seguinte foi a caracterização gravimétrica do resíduo classe A. Em função da uniformidade do resíduo, oriundo da central de concreto, essa determinação foi realizada de forma visual, pois se observou que o resíduo tinha predominância em mais de $95 \%$ de restos de concreto.

Em função da natureza do resíduo classe A e considerando o estágio da obra, a empresa optou pela produção de agregados reciclados miúdos (uso da peneira do britador de $4,8 \mathrm{~mm}$ ) e graúdo (uso da peneira do britador de 12,5 mm). Foi priorizada a utilização do agregado reciclado em graute e concreto magro para a construção das áreas de vivência.

Em 11 de agosto de 2009 realizou-se a britagem piloto. Essa atividade foi iniciada após o treinamento dos operários para a operação do equipamento de britagem e para o correto monitoramento do processo. Em caráter de teste, foram britados $2 \mathrm{~m}^{3}$ de resíduo classe $\mathrm{A} e$ identificadas possíveis melhorias no processo. Após esse estudo, deu-se continuidade ao processo de britagem e seu monitoramento, enquanto as amostras dos agregados reciclados, nas granulometrias geradas, foram encaminhadas para o laboratório contratado pela empresa construtora (Figura 5).

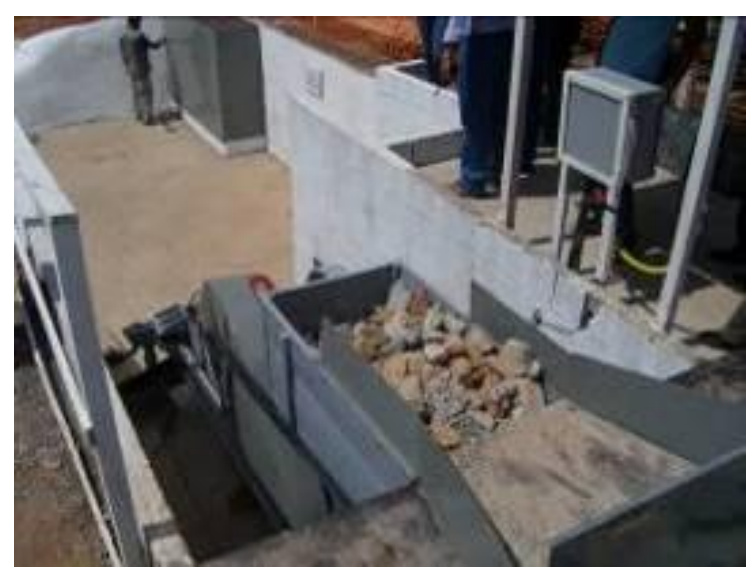

(b) 


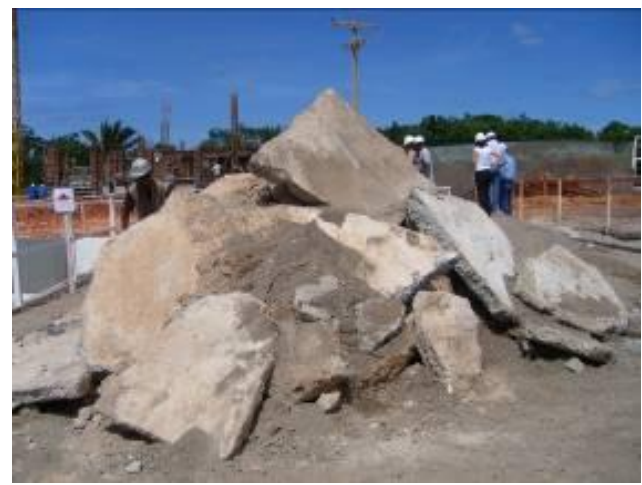

Figura 3 - Resíduo classe A

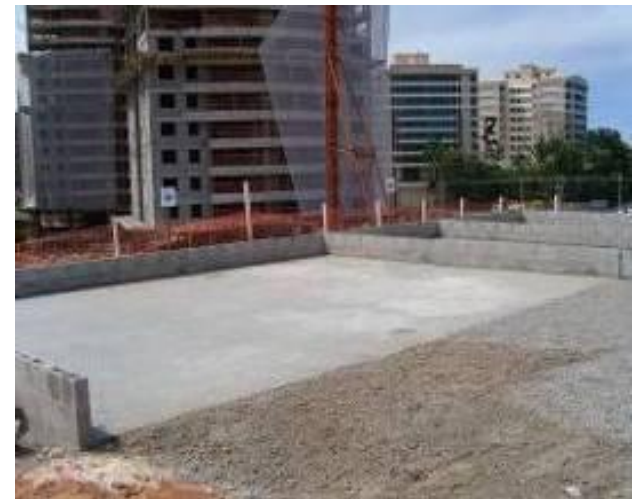

Figura 4 - Baias de agregado reciclado

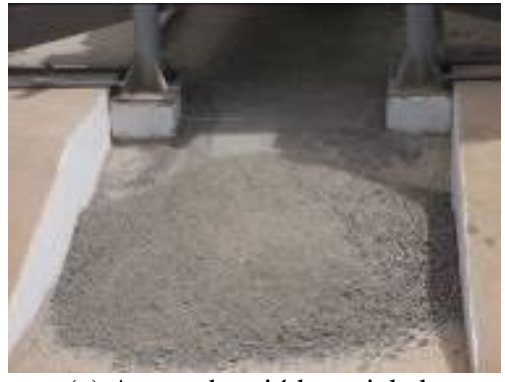

(a) Agregado miúdo reciclado

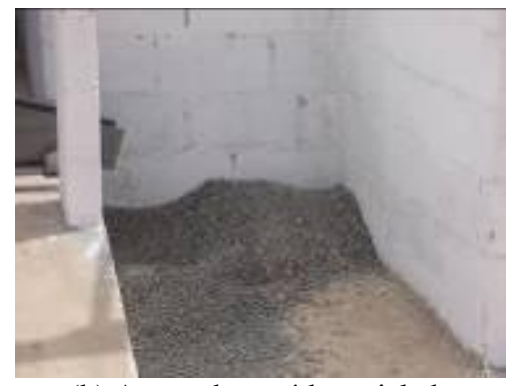

(b) Agregado graúdo reciclado

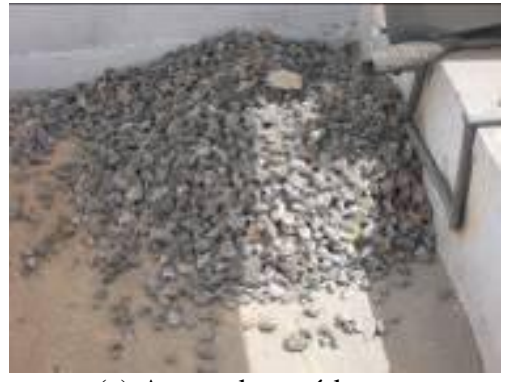

(c) Agregado graúdo sem granulometria

Figura 5 - Granulometrias do agregado reciclado

\section{Monitoramento do processo de reciclagem na obra}

O monitoramento do processo de reciclagem foi analisado em ciclos de quatro semanas, de modo a avaliar a evolução e as dificuldades do processo, conforme mostra a Tabela 1.

O primeiro ciclo foi considerado como período de avaliação da reciclagem no canteiro, e o monitoramento do processo de reciclagem estava sendo aprimorado. Nesse ciclo foram identificadas inconsistências nos dados coletados pelos operários.
A estratégia utilizada para melhorar a qualidade dessa coleta foi a designação por parte da empresa de um apontador, pelo prazo de quatro semanas, para monitorar continuamente o processo. Esse apontador ainda tinha a função de capacitar o servente responsável pela operação e alimentação do britador, para a coleta adequada de dados.

Uma das dificuldades no processo de britagem foi a grande dimensão do resíduo a ser britado, oriundo na usina de concretagem. A atividade extra de redução das dimensões do resíduo foi realizada durante todo o estudo e influenciou 
diretamente na produtividade global do processo de reciclagem e nos custos associados.

No segundo ciclo o processo de reciclagem conseguiu uma significativa melhoria em relação ao primeiro ciclo, tanto do ponto de vista de produção (incremento de $68,4 \%$ do volume de resíduo britado), quanto de produtividade do equipamento (incremento de $50 \%$ de produtividade), conforme mostra a Tabela 1.

Entretanto, observou-se por meio da análise de dados que o processo ainda possuía grande potencial de melhoria, devido ao longo tempo identificado para a preparação do processo de reciclagem, transporte e armazenamento do agregado reciclado. Em um turno de $8 \mathrm{~h}$ britavam-se $4 \mathrm{~m}^{3}$ de resíduo, sendo a produtividade do equipamento nesse ciclo de 1,8 $\mathrm{m}^{3} / \mathrm{h}$. Isso significava uma produtividade global de $0,5 \mathrm{~m}^{3} / \mathrm{h}$ e um tempo de $6 \mathrm{~h}$ para a preparação do processo de reciclagem, transporte e armazenamento do agregado reciclado.

No terceiro ciclo, a produção do processo de reciclagem caiu consideravelmente nas três semanas seguintes $(11,5 \%$ a menos em relação ao segundo ciclo), devido a dificuldades de relacionamento entre os membros da equipe de operação da reciclagem. Por outro lado, observou-se maior produtividade do equipamento de reciclagem, alcançando uma média de $2,20 \mathrm{~m}^{3} / \mathrm{h}$ e aumento de $50 \%$ na produtividade global. Apesar desse incremento, ainda foram observadas oportunidades de melhoria na produtividade global.

No quarto ciclo, foram propostas alterações de configuração do processo de reciclagem visando aumentar a produção e a produtividade global do processo de reciclagem. A proposta foi eliminar o controle rigoroso de saída dos agregados reciclados, reduzindo os tempos para contagem dos volumes produzidos, para tornar mais rápido o transporte e o armazenamento.
Como consequência dessa nova estratégia, eliminou-se o apontador (tarefa que passou a ser realizada pelo servente), reduzindo o custo do processo. Houve ainda um aumento de $28,3 \%$ na produção do resíduo e um aumento na produtividade global, passando para $1,00 \mathrm{~m}^{3} / \mathrm{h}$.

\section{Caracterização do agregado reciclado}

Avaliando as características da fração graúda dos agregados reciclados gerados nessa obra, com base na NBR 15116 (ABNT, 2004h), o agregado foi classificado como agregado de resíduo de concreto (ARC), por possuir mais de $90 \%$ de sua fração graúda formada por fragmentos à base de cimento Portland e rochas.

Os agregados reciclados (miúdo - AM1, graúdo AM2 e graúdo sem granulometria - AM3) foram caracterizados por um laboratório de tecnologia contratado pela obra, e seus resultados foram avaliados tendo como referência os parâmetros estabelecidos na NBR 15116 (ABNT, 2004h). Os resultados obtidos e os referenciais utilizados estão apresentados na Tabela 2.

\section{Produção, aplicação e avaliação de desempenho do agregado reciclado}

A partir dos resultados de caracterização dos agregados, encomendou-se ao laboratório contratado pela empresa construtora o desenvolvimento de traços para confecção de concreto magro e graute com a utilização dos agregados reciclados gerados. A premissa passada ao laboratório consistiu na máxima utilização do agregado reciclado, desde que fossem garantidas as características e os padrões de desempenho normativo dos produtos em questão. Os traços propostos e validados pelo laboratório especializado estão consolidados na Tabela 3.

\begin{tabular}{|c|c|c|c|c|c|c|c|c|}
\hline \multirow[b]{2}{*}{ Período } & \multirow[b]{2}{*}{$\begin{array}{c}\text { Volume } \\
\text { total de } \\
\text { resíduo } \\
\left(\mathbf{m}^{3}\right)\end{array}$} & \multicolumn{4}{|c|}{ Agregado reciclado (volume $\mathbf{m}^{3}$ ) } & \multirow[b]{2}{*}{$\begin{array}{c}\text { Volume de } \\
\text { agregado/ } \\
\text { Volume de } \\
\text { resíduo }\end{array}$} & \multirow[b]{2}{*}{$\begin{array}{c}\text { Produtividade } \\
\text { do } \\
\text { equipamento* } \\
\left(\mathrm{m}^{3} / \text { hora }\right)\end{array}$} & \multirow[b]{2}{*}{$\begin{array}{c}\text { Produtividade } \\
\text { global do } \\
\text { processo** } \\
\left(\mathbf{m}^{3} / \text { hora }\right)\end{array}$} \\
\hline & & Miúdo & Graúdo & $\begin{array}{c}\text { Graúdo } \\
\text { (sem } \\
\text { granulo- } \\
\text { metria) }\end{array}$ & $\begin{array}{c}\text { Volume } \\
\text { total de } \\
\text { agregado } \\
\text { reciclado } \\
\left(\mathrm{m}^{3}\right)\end{array}$ & & & \\
\hline Ciclo $1\left(1^{\mathrm{a}} \mathrm{a} 4^{\mathrm{a}}\right.$ sem $)$ & 57 & 15,7 & 12,9 & 26,0 & 54,7 & 0,96 & 1,2 & 0,50 \\
\hline Ciclo $2\left(5^{\mathrm{a}}\right.$ a $\left.8^{\mathrm{a}} \mathrm{sem}\right)$ & 96 & 16,8 & 19,3 & 43,3 & 79,3 & 0,83 & 1,8 & 0,50 \\
\hline Ciclo $3\left(8^{\mathrm{a}}\right.$ a $\left.12^{\mathrm{a}} \mathrm{sem}\right)$ & 86 & 14,0 & 14,7 & 39,0 & 67,6 & 0,78 & 2,2 & 0,75 \\
\hline Ciclo $4\left(13^{\mathrm{a}}\right.$ a $\left.16^{\mathrm{a}} \mathrm{sem}\right)$ & 138 & 22,08 & 22,08 & 66,24 & 110,4 & 0,80 & 2,0 & 1,00 \\
\hline
\end{tabular}

* Produtividade do equipamento: relação entre a quantidade de resíduo britado $\left(2 \mathrm{~m}^{3}\right)$ e determinado tempo (h).

** Produtividade global do processo de reciclagem: relação entre a quantidade total de resíduo britado e o tempo útil de trabalho em um dia $(8 \mathrm{~h})$. Estão incluídos o tempo de preparação da reciclagem, o tempo de processamento do resíduo pelo equipamento, o tempo para contagem das caixas e o tempo de transporte e armazenamento do agregado reciclado.

Tabela 1 - Indicadores do processo de reciclagem no canteiro 


\begin{tabular}{|c|c|c|c|c|c|c|}
\hline \multirow{2}{*}{ Ensaios } & \multicolumn{2}{|c|}{ AM 1} & \multicolumn{2}{|c|}{ AM 2} & \multicolumn{2}{|c|}{ AM 3} \\
\hline & Ensaio & Norma* & Ensaio & Norma* & Ensaio & Norma* \\
\hline Identificação da amostra & \multicolumn{2}{|c|}{ Areia reciclada } & \multicolumn{2}{|c|}{$\begin{array}{c}\text { Brita reciclada } \\
12,5 \mathrm{~mm} \\
\end{array}$} & \multicolumn{2}{|c|}{$\begin{array}{c}\text { Brita reciclada } \\
31,5 \mathrm{~mm}\end{array}$} \\
\hline Módulo de finura (NBR 7211) & 3,26 & - & 5,87 & - & 7,46 & - \\
\hline $\begin{array}{l}\text { Dimensão máxima característica (mm) } \\
\text { (NBR 7211) }\end{array}$ & 6,3 & - & 12,5 & - & 31,5 & - \\
\hline Massa unitária (kg/m3) (NBR 7251) & 1,28 & - & 1,22 & - & 1,21 & - \\
\hline Massa específica (g/cm3) (NM 52) & 2,37 & - & - & - & - & - \\
\hline Massa específica (g/cm3) (NM 53) & - & - & 2,33 & 7,0 & 2,44 & 7,0 \\
\hline Materiais pulverulentos (\%) (NM 46) & 9,2 & 15,0 & 2,0 & 10,0 & 0,6 & 10,0 \\
\hline Coeficiente de inchamento (NBR 6467) & 1,20 & - & & & & \\
\hline Absorção de água (\%) (NBR NM 53) & - & - & 9,0 & 7,0 & 6,2 & 7,0 \\
\hline $\begin{array}{l}\text { Teor de argila em torrões e materiais } \\
\text { friáveis }(\%) \text { (NBR } 7218)\end{array}$ & 0,20 & 2,0 & 0,10 & 2,0 & 0,2 & 2,0 \\
\hline
\end{tabular}

* Parâmetros da NBR 15116 (ABNT, 2004h)

Legenda: AM 1: agregado miúdo reciclado; AM 2: agregado graúdo reciclado; AM 3: agregado graúdo sem granulometria reciclado.

Tabela 2 - Caracterização dos agregados reciclados do Estudo de Caso 3

\begin{tabular}{|c|c|c|c|}
\hline \multicolumn{4}{|c|}{ TRAÇOS COM AGREGADO RECICLADO - ESTUDO DE CASO 3} \\
\hline \\
\hline Material & $\begin{array}{c}\text { Traço unitário } \\
\text { (em massa) }\end{array}$ & Massas (kg) & Volumes (litros) \\
\hline Cimento CP II - Z & 1 & $1 \mathrm{saco}=50 \mathrm{~kg}$ & $1 \mathrm{saco}=50 \mathrm{~kg}$ \\
\hline Areia natural & 1,064 & 53,2 & 44,3 \\
\hline Areia reciclada $(6,3 \mathrm{~mm})$ & 0,456 & 22,8 & 19,6 \\
\hline Brita reciclada $(12,5 \mathrm{~mm})$ & 2,177 & 108,8 & 89,2 \\
\hline Água & 0,600 & 30 & 30 \\
\hline Aditivo Cemix 2000 & $0,50 \%$ & $250 \mathrm{ml}$ & $250 \mathrm{ml}$ \\
\hline \multicolumn{4}{|c|}{ GRAUTE (20 MPa) } \\
\hline Material & $\begin{array}{l}\text { Traço unitário } \\
\text { (em massa) }\end{array}$ & Massas (kg) & Volumes (litros) \\
\hline Cimento CP II - Z & 1 & $1 \mathrm{saco}=50 \mathrm{~kg}$ & $1 \mathrm{saco}=50 \mathrm{~kg}$ \\
\hline Areia natural & 0,917 & 45,9 & 38,2 \\
\hline Areia reciclada $(6,3 \mathrm{~mm})$ & 0,393 & 19,7 & 16,9 \\
\hline Brita reciclada $(12,5 \mathrm{~mm})$ & 1,996 & 99,8 & 81,8 \\
\hline Água & 0,550 & 27,5 & 27,5 \\
\hline Aditivo Cemix 2000 & $0,50 \%$ & $250 \mathrm{ml}$ & $250 \mathrm{ml}$ \\
\hline \multicolumn{4}{|c|}{ CONCRETO MAGRO (10 MPa) } \\
\hline Material & $\begin{array}{c}\text { Traço unitário } \\
\text { (em massa) }\end{array}$ & Massas (kg) & Volumes (litros) \\
\hline Cimento CP II - Z & 1 & $1 \mathrm{saco}=50 \mathrm{~kg}$ & $1 \mathrm{saco}=50 \mathrm{~kg}$ \\
\hline Areia reciclada $(6,3 \mathrm{~mm})$ & 2,637 & 131,9 & 128,8 \\
\hline Brita reciclada $(31,5 \mathrm{~mm})$ & 3,327 & 166,4 & 137,5 \\
\hline Água & 0,820 & 41,0 & 41,0 \\
\hline
\end{tabular}

Tabela 3 - Traços com agregado reciclado - Estudo de Caso 3

$\mathrm{O}$ uso dos materiais com agregado reciclado na obra iniciou-se com a produção de graute de 16 $\mathrm{MPa}$ para utilização nos pilaretes da área de convivência do canteiro, conforme a Figura 6. Os agregados miúdos e graúdos reciclados também foram utilizados na regularização de vias de acesso do canteiro de obras, onde seria utilizado agregado natural (Figura 7).
O mesmo laboratório que definiu os traços ensaiou os materiais propostos, e os resultados de desempenho mostraram que todos os traços atenderam aos valores mínimos do padrão normativo para o ensaio de resistência a compressão, conforme mostra a Tabela 4. 


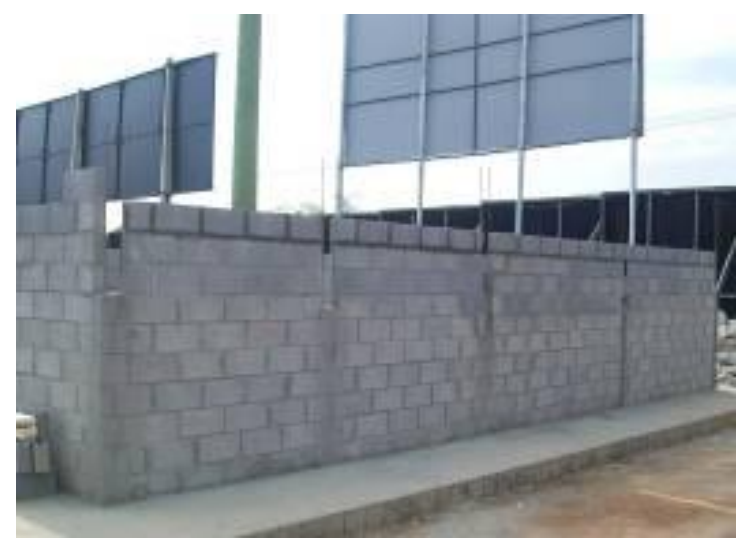

Figura 6 - Aplicação do graute $16 \mathrm{MPa}$

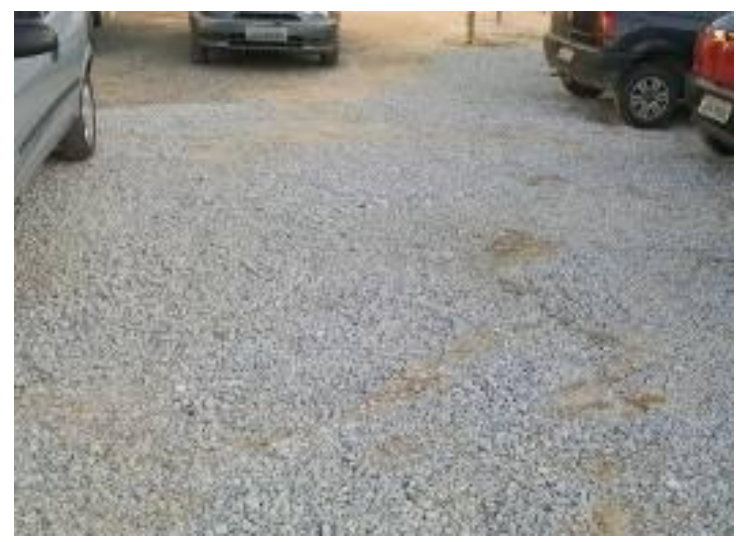

Figura 7 - Regularização de vias de acesso

\begin{tabular}{l|c|c|c}
\hline Material & $\begin{array}{c}\text { Resistência à } \\
\text { compressão (3 dias) }\end{array}$ & $\begin{array}{c}\text { Resistência à } \\
\text { compressão (7 dias) }\end{array}$ & $\begin{array}{c}\text { Resistência à } \\
\text { compressão } \\
\text { (28 dias) }\end{array}$ \\
\hline Graute $16 \mathrm{MPa}$ & 17,7 & 20,0 & 25,6 \\
\hline Graute $20 \mathrm{MPa}$ & 18,6 & 20,8 & 28,7 \\
\hline Concreto magro $10 \mathrm{MPa}$ & - & 6,1 & 13,25 \\
\hline
\end{tabular}

Tabela 4 - Avaliação de desempenho dos materiais

\section{Avaliação econômica e ambiental do processo de reciclagem}

A avaliação econômica foi realizada com base na premissa de ganho econômico do processo de reciclagem no canteiro, por metro cúbico, que consistiu no valor relativo ao custo do agregado natural $\left(\mathrm{m}^{3}\right)$, acrescido do valor para bota-fora de entulho $\left(\mathrm{m}^{3}\right)$ e subtraído do custo para produção do agregado reciclado $\left(\mathrm{m}^{3}\right)$, conforme mostra a Fórmula 1.

GER $(\mathrm{m} 3)=\mathrm{CAN}(\mathrm{m} 3)+\mathrm{CBF}(\mathrm{m} 3)-\mathrm{CAR}(\mathrm{m} 3)$

Onde:

GER - Ganho econômico da reciclagem

CAN - Custo do agregado natural

CBF - Custo de bota-fora do entulho

\section{CAR - Custo do agregado reciclado}

Os custos do agregado natural e do bota-fora foram informados pela própria empresa. O custo para produção do agregado reciclado foi obtido a partir da avaliação do processo de reciclagem nas 16 primeiras semanas, considerando as melhorias implantadas. Nessa composição foram considerados os custos de mão de obra direta com encargos, equipamentos, energia e manutenção. A composição de custos elaborada para o cálculo dos custos do agregado reciclado pode ser observada em Evangelista (2009). Vale registrar que, pelo caráter da pesquisa, o equipamento de britagem não gerou custo de locação para a empresa.

Aplicando a Fórmula 1 e segundo os dados coletados na obra, o ganho econômico do processo de reciclagem, no referido estudo de caso, 
totalizou $\mathrm{R} \$ 43,82$ por metro cúbico de agregado reciclado, conforme mostra o Quadro 2.

Em função do porte da obra, dos padrões internos de organização e sinalização, critérios de segurança estabelecidos e configuração do canteiro, realizou-se um investimento significativo pela empresa para implantação da central de britagem. Além disso, a empresa contratou serviços especializados de consultoria e controle tecnológico para apoiar o processo. Todos os itens citados totalizaram um investimento total de $\mathrm{R} \$$ $15.686,90$, que se configurou na realidade deste estudo de caso. $\mathrm{O}$ investimento para implantação de uma central de reciclagem no canteiro é um item variável, que deverá ser avaliado a cada caso.
Para calcular o tempo de retorno do investimento realizado para estruturar a central de reciclagem e para a contratação de serviços técnicos especializados, o valor total do investimento foi dividido pelo ganho econômico unitário, concluindo que seria necessária a geração de aproximadamente $358 \mathrm{~m}^{3}$ de agregado reciclado.

Durante os quatro ciclos de reciclagem foram gerados $312 \mathrm{~m}^{3}$ e restaram $45,98 \mathrm{~m}^{3}$ a serem produzidos. Em função do amadurecimento do processo, estima-se que é possível uma produção de $160 \mathrm{~m}^{3}$ de agregado reciclado por mês, restando apenas mais uma semana e meia de britagem para pagar o investimento realizado.

\begin{tabular}{|c|c|}
\hline \multicolumn{2}{|l|}{ CUSTOS } \\
\hline Custo do agregado reciclado $\left(\mathrm{m}^{3}\right)$ & $\mathrm{R} \$ 29,02$ \\
\hline Custo do agregado natural $\left(\mathrm{m}^{3}\right)$ & $\mathrm{R} \$ 52,00$ \\
\hline Custo do bota-fora $\left(\mathrm{m}^{3}\right)$ & $\mathrm{R} \$ 20,84$ \\
\hline $\begin{array}{l}\text { (A) Ganho econômico = custo do agregado natural }+ \text { custo do bota-fora }- \text { custo do } \\
\text { agregado reciclado }\end{array}$ & $\mathbf{R} \$ \mathbf{4 3 , 8 2}$ \\
\hline $\begin{array}{l}\text { (B) Investimento para estruturar a central de reciclagem (infraestrutura física }+ \\
\text { transporte do britador) }\end{array}$ & $\mathbf{R} \$ \mathbf{8 . 9 5 6 , 9 0}$ \\
\hline (C) Contratação de serviços técnicos (consultoria + ensaios laboratoriais) & $\mathrm{R} \$ 6.730,00$ \\
\hline \multicolumn{2}{|l|}{ RECUPERAÇÃO DO INVESTIMENTO } \\
\hline Ganho econômico por $\mathrm{m}^{3}$ de agregado reciclado (A) & $\mathrm{R} \$ 43,82$ \\
\hline Investimento total realizado $(\mathrm{B}+\mathrm{C})$ & $\mathrm{R} \$ 15.686,90$ \\
\hline (D) Volume de agregado a ser reciclado para recuperar investimento realizado $\left(\mathrm{m}^{3}\right)$ & 357,98 \\
\hline (E) Volume de agregado reciclado no mês $1\left(\mathrm{~m}^{3}\right)$ & 54,70 \\
\hline (F) Volume de agregado reciclado no mês $2\left(\mathrm{~m}^{3}\right)$ & 79,30 \\
\hline (G) Volume de agregado reciclado no mês $3\left(\mathrm{~m}^{3}\right)$ & 67,60 \\
\hline (H) Volume de agregado reciclado no mês $4\left(\mathrm{~m}^{3}\right)$ & 110,40 \\
\hline $\begin{array}{l}\text { (I) Diferença do volume de agregado a ser reciclado para recuperar investimento (D-E-F) } \\
\left(\mathrm{m}^{3}\right)\end{array}$ & 45,98 \\
\hline (J) Volume estimado de agregado reciclado para os meses subsequentes $\left(\mathrm{m}^{3} / \mathrm{mês}\right)$ & 160,00 \\
\hline $\begin{array}{l}\text { (K) Prazo para complementar a produção de agregado reciclado necessário para recuperar } \\
\text { o investimento realizado (meses) }(\mathrm{G} / \mathrm{H})\end{array}$ & 0,30 \\
\hline $\begin{array}{l}\text { Prazo total de produção de agregado reciclado necessário para recuperar o } \\
\text { investimento realizado (meses) }(K+4 \text { meses iniciais) }\end{array}$ & 4,30 \\
\hline \multicolumn{2}{|l|}{ RETORNO ECONÔMICO } \\
\hline $\begin{array}{l}\text { Ganho estimado para os meses subsequentes à recuperação do investimento (R\$/mês) } \\
\left(\begin{array}{l}\text { ( x J) }\end{array}\right.\end{array}$ & $\mathbf{R} \$ \mathbf{7 . 0 1 1 , 2 7}$ \\
\hline
\end{tabular}

Quadro 2 - Análise econômica do Estudo de Caso 3

A partir do momento da obtenção do retorno do investimento, todo o resultado mensal financeiro, decorrente do volume de agregado reciclado gerado, se configura como retorno econômico, como pode ser visto no Quadro 2. Vale ressaltar que a lógica utilizada nesta análise econômica é comum para a maioria dos casos de reciclagem em canteiros de obras, no entanto, pelo caráter variável de cada empreendimento, faz-se necessária uma análise criteriosa dos custos associados para cada caso específico. 
No aspecto ambiental, nas 16 semanas, $312 \mathrm{~m}^{3}$ de agregado natural deixaram de ser consumidos e 377 $\mathrm{m}^{3}$ de entulho de obra deixaram de ser destinados a aterros ou dispostos de forma inadequada. É importante destacar que todas as precauções foram tomadas para minimizar os impactos ambientais causados pela geração de particulados e pelo ruído do processo, iniciando-se pelo adequado estudo de implantação da central de reciclagem. A equipe de segurança do trabalho atuou de forma intensiva para evitar quaisquer danos aos operadores envolvidos, disponibilizando todos os equipamentos de proteção individual necessários.

\section{Sistematização da reciclagem em canteiros de obras}

A partir da pesquisa bibliográfica e das observações realizadas durante os estudos de caso, foi possível propor uma sistematização do processo de reciclagem em canteiros de obra por meio de fluxograma e procedimento operacional.

A elaboração do fluxograma teve por objetivo a demonstração gráfica de todas as etapas do processo, permitindo a visualização simplificada e global de todas as etapas e sua sequência lógica, assim como as inter-relações entre elas (Figura 8). O fluxograma se apresenta como ferramenta de sensibilização junto a técnicos, engenheiros e donos de empresas construtoras, no sentido de apresentar a viabilidade dessa prática nos canteiros e a possibilidade de compatibilizar essa atividade ao fluxo de execução das obras.

A elaboração do procedimento visou facilitar a incorporação desse processo ao sistema da qualidade das empresas que já possuem essa prática, assim como uma melhor sistematização para aquelas que ainda não iniciaram a implantação desse tipo de programa.

O procedimento descreve com maior detalhamento as etapas apresentadas no fluxograma, complementando-o e trazendo uma sequência das atividades com seus respectivos responsáveis, modelos de formulários que apoiarão a coleta e análise das informações críticas da reciclagem e controle dos registros gerados. Esse procedimento pode ser encontrado em Evangelista (2009).

As etapas críticas descritas no procedimento são:

(a) diagnóstico inicial da obra: caracterização geral da obra, identificação das possíveis aplicações para o agregado reciclado, avaliação do cronograma físico e layout da obra, definição do processo de segregação do resíduo classe A e indicação do responsável pelo processo de reciclagem no canteiro; (b) definição das aplicações do agregado reciclado: indicação da aplicação do agregado reciclado (obras de pavimentação viária ou preparo de concreto sem função estrutural) e as granulometrias necessárias;

(c) estruturação do processo de reciclagem: definição da implantação da central de reciclagem (equipamentos, layout e logística) e elaboração do planejamento;

(d) caracterização do resíduo classe A: análise gravimétrica do resíduo classe A da obra, que consiste na determinação do percentual de cada material constituinte na composição geral do resíduo;

(e) monitoramento do processo de reciclagem: realização da britagem piloto, britagem inicial de 1 $\mathrm{m}^{3}$ para validação e ajustes no processo, amostragem do agregado reciclado para caracterização e, na sequência, controle do processo de reciclagem, com registro do volume de resíduo britado e do agregado reciclado por granulometria (miúdo e graúdo);

(f) caracterização do agregado reciclado: realização dos ensaios no agregado reciclado segundo a NBR 15116 (ABNT, 2004h), análise comparativa dos resultados e validação da utilização do agregado gerado;

(g) produção piloto do material com agregado reciclado: definição e produção do material de referência com agregado natural, que servirá de parâmetro para comparação com os materiais produzidos com o agregado reciclado em diversos percentuais de substituição e produção dos materiais experimentais, substituindo parcial e totalmente os agregados naturais por reciclados;

(h) avaliação do desempenho do material com agregado reciclado: realização dos ensaios nos materiais de referência e experimentais, segundo as normas técnicas aplicáveis a esses materiais, análise comparativa dos resultados e definição do percentual de substituição que represente o maior aproveitamento de agregados reciclados, desde que garantidas as características e os padrões de desempenho requeridos para o material;

(i) aplicação do material e rastreabilidade: produção do material com agregado reciclado na fração de substituição definida e controle de sua aplicação; e

(j) avaliação do processo de reciclagem: análise crítica do processo de reciclagem no canteiro, considerando os aspectos técnicos, econômicos e ambientais. 


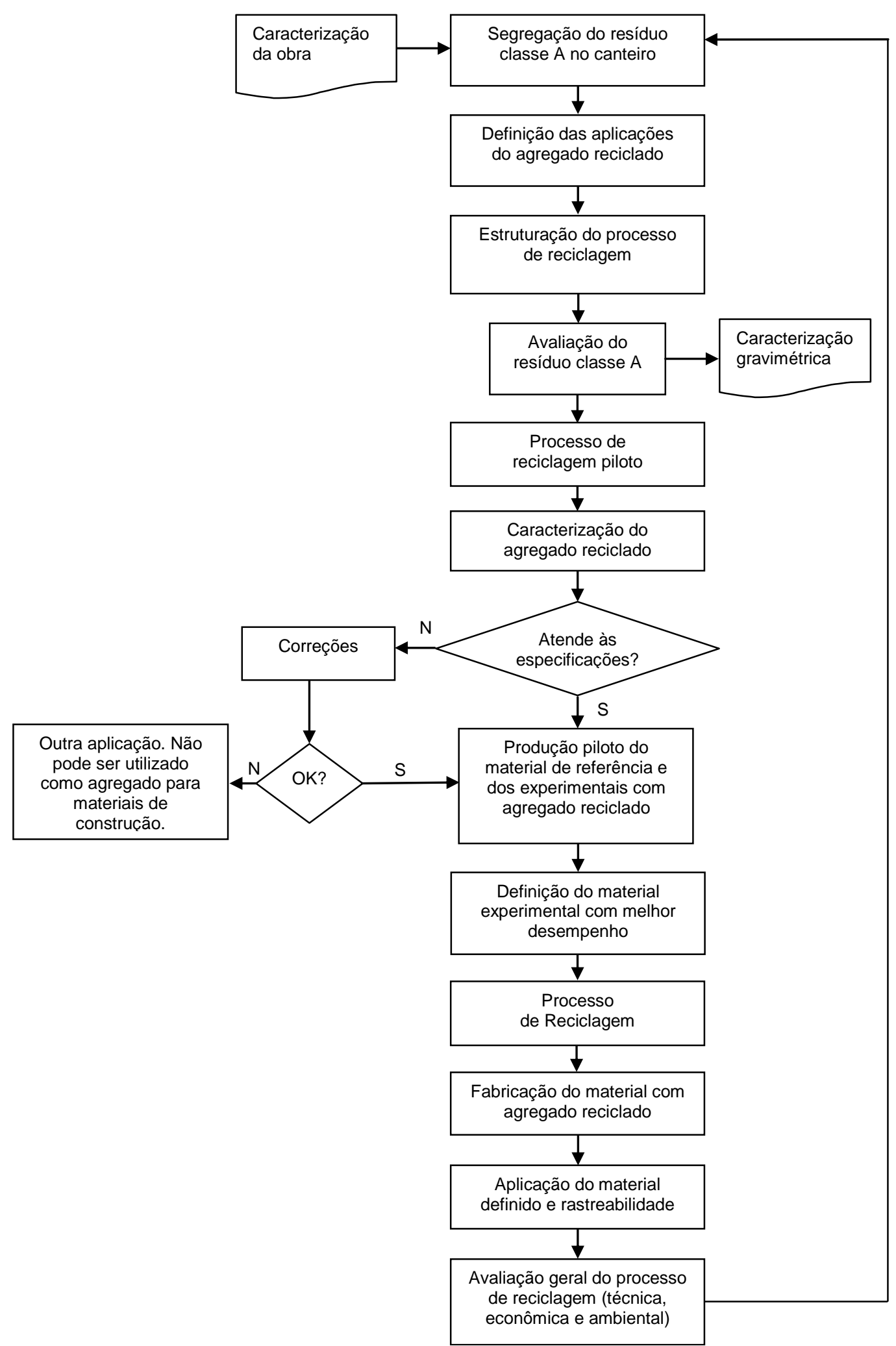

Figura 8 - Fluxograma de reciclagem de resíduos classe A em canteiros de obras 


\section{Conclusão}

Diante de todas as informações contidas neste trabalho, seja por meio das referências apresentadas ou dos resultados obtidos nos três estudos de caso de experiências de reciclagem em canteiros, é evidente o caráter crítico do manejo dos resíduos de construção no Brasil. A situação apresentada reforça a necessidade de um movimento urgente e conjunto de toda a sociedade, no sentido de propor alternativas sustentáveis para minimizar seus impactos ambientais e promover sua destinação responsável.

O cenário da geração dos RCC na RMS é preocupante em função do forte crescimento do mercado imobiliário, da realização de obras de infraestrutura e do déficit habitacional. Além dos fatores citados, é possível acrescentar os entraves quanto à destinação adequada, levando-se em conta o esgotamento das áreas de recebimento para RCC, a inexistência de áreas de transbordo, triagem e reciclagem e a inércia do poder público municipal diante dessa situação.

O RCC, constituído em sua maioria de resíduos classe A, com alto potencial de reciclagem, pode $\mathrm{e}$ deve ser reaproveitado, reutilizado ou reciclado como forma de minimizar os nocivos impactos ambientais que atualmente vêm ocorrendo em toda a RMS, em virtude de seu descarte inadequado.

Com base no trabalho realizado, conclui-se pela viabilidade da reciclagem em canteiros de obras. No entanto, é importante ressaltar que diversos aspectos devem ser considerados para o sucesso dessa prática, a exemplo da correta segregação dos resíduos classe $\mathrm{A}$, da avaliação técnica dos agregados reciclados e da análise de desempenho dos materiais gerados com esses agregados.

Constatou-se que a reciclagem em canteiros é passível de ser sistematizada, na forma de etapas e procedimentos, e que essa sistematização contribui para a ampliação dos conhecimentos técnicos e sua implantação nos canteiros de obras.

Com base nas experiências estudadas, verificou-se que há benefícios econômicos e ambientais decorrentes da prática da reciclagem em canteiros de obras. No aspecto ambiental, um volume significativo de RCC deixou de ser destinado de forma irregular ou de ser enviado para aterro. Cerca de $80 \%$ desse volume se converteu em agregado reciclado, que substituiu a utilização de agregado natural. Foi também promovida a responsabilidade social e ambiental das empresas e dos profissionais envolvidos. No aspecto econômico, apesar do investimento realizado e dos gastos diretos para reciclar o resíduo classe A nos canteiros, foi possível constatar a possibilidade de retorno financeiro decorrente da economia realizada com bota-fora e aquisição de agregado natural.

Espera-se com este trabalho que o processo de reciclagem nos canteiros de obras possa ser disseminado e que sua prática seja ampliada como alternativa sustentável para destinação dos resíduos classe A gerados pela atividade construtiva.

\section{Referências}

\section{ASSOCIAÇÃO BRASILEIRA DE NORMAS}

TÉCNICAS. NBR 10004: resíduos sólidos:

classificação. Rio de Janeiro, 2004a.

\section{ASSOCIAÇÃO BRASILEIRA DE NORMAS \\ TÉCNICAS. NBR 10006: procedimento para obtenção de extrato solubilizado de resíduos sólidos. Rio de Janeiro, 2004b.}

\section{ASSOCIAÇÃO BRASILEIRA DE NORMAS} TÉCNICAS. NBR 10007: amostragem de resíduos sólidos. Rio de Janeiro, 2004c.

\section{ASSOCIAÇÃO BRASILEIRA DE NORMAS}

TÉCNICAS. NBR 15112: resíduos da construção civil e resíduos volumosos: áreas de transbordo e triagem: diretrizes para projeto, implantação e operação. Rio de Janeiro, 2004d.

\section{ASSOCIAÇÃO BRASILEIRA DE NORMAS TÉCNICAS. NBR 15113: resíduos sólidos da construção civil e resíduos inertes: aterros: diretrizes para projeto, implantação e operação. Rio de Janeiro, 2004e.}

\section{ASSOCIAÇÃO BRASILEIRA DE NORMAS} TÉCNICAS. NBR 15114: resíduos sólidos da construção civil: áreas de reciclagem: diretrizes para projeto, implantação e operação. Rio de Janeiro, 2004f.

\section{ASSOCIAÇÃO BRASILEIRA DE NORMAS}

TÉCNICAS. NBR 15115: agregados reciclados de resíduos sólidos da construção civil: execução de camadas de pavimentação: procedimentos. Rio de Janeiro, 2004g.

\section{ASSOCIAÇÃO BRASILEIRA DE NORMAS}

TÉCNICAS. NBR 15116: agregados reciclados de resíduos sólidos da construção civil: utilização em pavimentação e preparo de concreto sem função estrutural: requisitos. Rio de Janeiro, 2004h.

\section{BLUMENSCHEIN, R. N. Gestão de Resíduos} Sólidos em Canteiros de Obras. Brasília, DF: Centro de Apoio ao Desenvolvimento

Tecnológico, Universidade de Brasília, 2007.

Dossiê Técnico. 
BOSSINK, B. A. G.; BROUWERS, H. J. H. Construction Waste: quantification and source evaluation. Journal of Construction Engineering and Management, Amsterdam, v. 122, n. 1, p. 5560, Mar. 1996.

BRASIL. Ministério do Meio Ambiente. Conselho Nacional do Meio Ambiente. Resolução n ${ }^{0}$ 307, de 5 de Julho de 2002. Estabelece diretrizes, critérios e procedimentos para a gestão dos resíduos da construção civil. Brasília, DF, 2002. Disponível em:

<http://www.mma.gov.br/port/conama/res/res02/re s30702.html>. Acesso em: 13 set. 2004.

CARNEIRO, A. P. et al. Reciclagem de Entulho para Produção de Materiais de Construção: Projeto Entulho Bom. Salvador: EDUFBA: Caixa Econômica Federal, 2001.

\section{EVANGELISTA, P. P. A. Alternativa}

Sustentável para Destinação de Resíduos Classe A: diretrizes para reciclagem em canteiros de obras. 2009. 152 f. Dissertação (Mestrado em Engenharia Ambiental Urbana) - Escola Politécnica, Universidade Federal da Bahia, Salvador, 2009.

GOONAN, T. G. Recycled Aggregates: profitable resource conservation. Denver: U.S. Geological Survey, 2000. Disponível em: <http://pubs.usgs.gov/fs/fs-0181-99/fs-018199so.pdf>. Acesso em: 05 jun. 2009.

JOHN, V. M. Reciclagem de Resíduos na Construção Civil: contribuição para metodologia de pesquisa e desenvolvimento. 2000. $113 \mathrm{f}$. Tese (Livre Docência) - Escola Politécnica, Universidade de São Paulo, São Paulo, 2000.

LEITE, M. B. Avaliação de Propriedades Mecânicas de Concretos Produzidos com Agregados Reciclados de Resíduos de Construção e Demolição. 2001. 270 f. Tese (Doutorado em Engenharia Civil) - Escola de Engenharia, Universidade Federal do Rio Grande do Sul, Porto Alegre, 2001.

LEVY, S. M. Contribuição ao Estudo da Durabilidade de Concretos, Produzidos com Resíduos de Concreto e Alvenaria. 2001. 199 f. Tese (Doutorado em Engenharia Civil) Departamento de Engenharia de Construção Civil, Escola Politécnica, Universidade de São Paulo, São Paulo, 2001.

LORDÊLO, P. M.; EVANGELISTA, P. P. A.; FERRAZ, T. G. A. Gestão de Resíduos na Construção Civil: redução, reutilização e reciclagem. Salvador: SENAI-BA, 2007.
MINAS GERAIS. Sindicato da Indústria da Construção Civil. Alternativas para a Destinação de Resíduos da Construção Civil. Belo Horizonte, 2006.

MOTTA, R. S. Estudo Laboratorial de Agregado Reciclado de Resíduo Sólido da Construção Civil para Aplicação em Pavimentação de Baixo Volume de Tráfego. 2005. 134 f. Dissertação (Mestrado em Engenharia de Transportes) - Escola Politécnica, Universidade de São Paulo, São Paulo, 2005.

OLIVEIRA, P. E. S.; OLIVEIRA, J. T. R.; FERREIRA, S. R. M. Avaliação do Desempenho do Concreto com uso de Agregado de Resíduos de Construção e Demolição - RCD. In: CONGRESSO BRASILEIRO DO CONCRETO, 50., 2008, Salvador. Anais... São Paulo: IBRACON, 2008. 1 CD-ROM.

PINTO, T. P. Metodologia para a Gestão Diferenciada de Resíduos Sólidos da Construção Urbana. 1999. 189 f. Tese (Doutorado em Engenharia Civil) - Departamento de Engenharia de Construção Civil, Escola Politécnica, Universidade de São Paulo, São Paulo, 1999.

PUIG, T. F. La Problemática de la Gestión de los Residuos de Construcción: una aproximación al estado actual de la cuestión. In: CONVENCIÓN DE LA ARQUITECTURA TÉCNICA, 4., 2006, Valladolid. Anais... Barcelona: Aparejadores Barcelona, 2006. Disponível em: $<$ http://es.csostenible.net/files/gestion_residuos_ca st.pdf >. Acesso em: 07 jun. 2009.

SALES, A. T. C.; SANTOS, D. G. Aplicação de Agregados Reciclados de Resíduos de Construção em Blocos Pré-Moldados de Vedação. In: ENCONTRO NACIONAL SOBRE APROVEITAMENTO DE RESÍDUOS NA CONSTRUÇÃO, 2009, Feira de Santana. Anais... Porto Alegre: ANTAC, 2009. p. 496-505.

SALVADOR. Empresa de Limpeza Urbana (LIMPURB). Relatório Anual de Atividades da LIMPURB: 2006. Salvador, 2006.

SOUZA, U. E. L. et al. Diagnóstico e Combate à Geração de Resíduos na Produção de Obras de Construção de Edifícios: uma abordagem progressiva. Ambiente Construído, Porto Alegre, v. 4, n. 4, p. 33-46, dez. 2004. 
TENÓRIO, J. J. L. et al. Concretos Produzidos com Agregados de RCD Reciclado Visando Uso Estrutural. In: CONGRESSO BRASILEIRO DO CONCRETO, 50., 2008, Salvador. Anais... São Paulo: IBRACON, 2008. 1 CD-ROM.
VIEIRA, G. L.; DAL MOLIN, D. C. C. Viabilidade Técnica da Utilização de Concretos com Agregados Reciclados de Resíduos de Construção e Demolição. Ambiente Construído, Porto Alegre, v. 4, n. 4, p. 47-63, dez. 2004. 